TAPROBANICA, ISSN 1800-427X. April, 2009. Vol. 01, No. 01: pp. 66-73.

(C) Taprobanica Nature Conservation Society, 146, Kendalanda, Homagama, Sri Lanka.

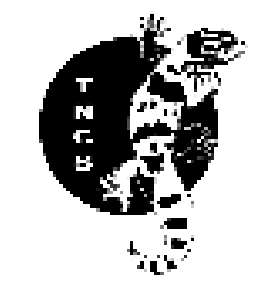

\title{
SOCIAL BEHAVIOURS OF CAPTIVE Trachypithecus cristatus (MAMMALIA: CERCOPITHECIDAE) IN THE NATIONAL ZOOLOGICAL GARDENS OF SRI LANKA
}

Submitted: 08 January 2009, Accepted: 11 January 2009

\author{
A. A. Thasun Amarasinghe ${ }^{1,2}$, W. Madhava S. Botejue ${ }^{1}$ and Lee E. Harding ${ }^{3,4}$ \\ ${ }^{1}$ Taprobanica Nature Conservation Society, 146, Kendalanda, Homagama, Sri Lanka \\ ${ }^{3}$ SciWrite Environmental Sciences Ltd. 2339 Sumpter Drive, Coquitlam, British Columbia, Canada \\ Corresponding authors: ${ }^{2}$ aathasun@gmail.com; ${ }^{4}$ harding@sciwrite.ca
}

\begin{abstract}
Trachypithecus cristatus (Silvered Leaf Monkey or Silvered Lutung) occur on the Malay Peninsula, Sumatra, Borneo and nearby islands and live mainly in uni-male, female-bonded groups. This study presents preliminary data on social behaviours for Silvered Leaf Monkey in captivity. Behavioural observations were conducted on one group (one adult male, four adult females, three juvenile males and four juvenile females). Data were collected on 30 of the 60 calendar days at the National Zoological Gardens, Dehiwala, Sri Lanka. All behaviours including agonistic and dominance-related, locomotion, feeding and infant-related behaviours were included in the analysis. Unlike in wild populations, we found a clear dominance hierarchy among females.
\end{abstract}

Key words: Trachypithecus cristatus, Captive Behaviour, Dominance, Hierarchy, Langur, Sri Lanka.

\section{Introduction}

Lutung, Langur, Leaf Monkey and Surili are common names for certain Asian and East Indian long-tailed, slender monkeys in the genera Trachypithecus, Semnopithecus and Presbytis. Lutung and Surili are Malay words that apply to the Southeast Asian genera Trachypithecus and
Presbytis, respectively, and may be preferable to Langur, a Hindi word that should perhaps be restricted to Semnopithecus, a mainly south Asian genus (Bernstein 1968; Brotoisworo 1979; Geissmann et al., 2004; Osterholtz et al., 2008; Weitzel \& Groves 1985). All have heavy eyebrows 
and, often, beardlike hairs on their chins and body heavily built (Phillips, 1980). Langurs are distributed in Sri Lanka, Western Ghats, Bhutan, Assam and Bangladesh, while Lutungs and Surilis occur throughout Indo-China, the Malay Peninsula, Archipelago, Bali, and Lombok (Francis, 2008). Silvered Leaf Monkeys (Trachypithecus cristatus) occur on the Malay Peninsula, Sumatra, Borneo and nearby islands. They live mainly in uni-male, female-bonded groups. Trachypithecus neonates are orange. Like other leaf monkeys, they are arboreal, move among the branches by both quadrupedal locomotion and semi-brachiation (Fleagle, 1977a), live in troops and feed on vegetation. Arboreal animals occupying upper story vegetation, which provide an unobstructed view of the surroundings, can easily avoid contact. It is therefore interesting that males regularly sought other males to display against. Although encounters were frequent, the cost to the participants was minimal because physical contact and injury rarely occurred (Poirier, 1968). T. cristatus shows a low level of aggression and frequent sociosexual, gestural, and vocal interactions within the social group, relative to other leaf monkeys (Roonwal \& Mohnot, 1977).

Trachypithecus species have relatively short lower legs and forearms (Washburn 1944), differences in musculature, and differences in the pelvis (Tague, 1993) compared to Presbytis species. These adaptations to more quadrupedal locomotion and less brachiation (Fleagle, 1977a, 1977b) reflect the feeding preferences of Trachypithecines for the middle and upper canopy, but not as high up or as far out on slender branches as Presbytis (Curtin, 1977).

Langurs, Lutungs and Surilis are often called Leaf Monkeys because of their diet, although typically over one-third of what they eat is seeds, buds, blossoms, and fruit. Like all colobines, they have a large, sacculated, ruminant-like stomach with microbial fermentation, an adaptation to a folivorous diet (Strasser \& Delson 1987). Although among the smaller of the Trachypithecus and Presbytis species, $T$. cristatus had the largest gastrointestinal tract (Chivers, 2001), a reflection of its higher intake of leaves and less fruit. Leaves may comprise up to $91 \%$ and fruit only $9 \%$ (Hock \& Sasekumar, 1979), the highest and lowest percentages, respectively, of all colobine species for which data were available (Caton, 1999; Yeager \& Kool, 2000). Most seed eating occurred during the period of maximum fruit production and fewer small-seeded, animal-dispersed fruits were eaten at other times. These included sweet, fleshy fruits, which most other colobines tend to avoid. Young leaf intake was greatest in months when fruit intake was low. Mature leaves were rarely eaten (Glyn, 1991; Kool, 1993). Although some Presbytis species have been seen to consume animal prey (Goodman, 1989), virtually $100 \%$ of the diet of these monkeys is plants.

T. cristatus has a polygynous, cooperative-breeding mating system. Single male/multifemale group sizes of about 10-40, as well as singles and smaller multi-males groups are the norm; in wild populations, communal nursing and other parental care is common and there is no evidence of a female hierarchy (Bernstein, 1968; Furuya, 1961; Roonwal \& Mohnot, 1977; Wolf \& Fleagle, 1977). Occasionally, a male from an all-male unit or an individual male will replace the male of a male/female group. Wolf \& Fleagle (1977) reported that, three months after a male take-over, all of the dependent infants in the group had disappeared and were assumed to have been killed by the new dominant male. This incident of supposed infanticide by an incoming male has been widely repeated, although actual infanticide was not observed (as it has in other Trachypithecus speciesBrotoisworo, 1979; Li \& Rogers, 2004; Zhao \& Pan, 2006 and Semnopithecus - Hrdy, 1974). It remains uncertain how often and under what circumstances infanticide occurs in T. cristatus (Newton \& Dunbar, 2001; Zhao \& Pan, 2006). The similarity of these observations to observations of male-takeovers and subsequent infanticide in Indian and Ceylonese Langurs (Hrdy, 1974) suggests a similar pattern of social change among all Langurs, which live in one-male groups. Borries et al. (1999) demonstrated the adaptive benefit (i.e., more progeny) of infanticide by an incoming male Hanuman Langur (Semnopithecus vetulus) after he takes over a troop from another male. The occurrence of male replacement suggests instability of multi-male organization in bisexual troops. Moreover, the different mortality rate between males and females and the unequal sex ratios forced by the formation of one-male troops, maintained high-tension levels among males competing for females (Kunkun, 1986). Genital swellings, which occur in some Cercopithecinae primate species that live in multi-female groups and are associated with oestrus, were examined in adult females by Shelmidine et al. (2007). They found that vulval swellings occurred minimally, did not increase during the period of receptivity, and were not attractive to males. 


\section{Materials and Methods}

Study Area: The National Zoological Gardens (NZG) is approximately 23 acres in extent (Karunarathna et al., 2008). It is located at a mean elevation of $20 \mathrm{~m}$ above sea level and belongs to the lowland wet zone of Sri Lanka. The NZG is situated at the intersection of $6^{\circ} 50^{\circ} \mathrm{N}$ and $79^{\circ} 54^{\prime} \mathrm{E}$, approximately $2 \mathrm{~km}$ away from Dehiwala town and $11 \mathrm{~km}$ away from Colombo (Weinman, 1957). The NZG receives $<2000 \mathrm{~mm}$ of mean annual rainfall, with mean annual temperature ranging from approximately $27.1{ }^{\circ} \mathrm{C}$ to $29.4{ }^{\circ} \mathrm{C}$ (Somasekaran, 1988). The NZG consists of several habitat types that can be categorized as man-made small grasslands, scrublands, several small ponds, home gardens and large shady trees (i.e. Ficus sp. Tabubbia sp.).

Study Group: A one-male/ multi-female group of Silvered Lutungs housed at the National Zoological Gardens in Sri Lanka was studied. The animals resided in a $25 \mathrm{~m}^{2}$ naturalistic outdoor enclosure during the whole day. At the beginning of the study, the group had one adult male $\left(\mathrm{Mm}^{*}\right)$, four adult females $\left(\mathrm{Fm}^{\mathrm{L} 1} \& \mathrm{Fm}^{\mathrm{L} 2}=\right.$ lactating, $\mathrm{Fm}^{\mathrm{P}}=$ pregnant and $\left.\mathrm{Fm}^{*}\right)$, three juvenile males $\left(\mathrm{Mj}^{1}, \mathrm{Mj}^{2}, \mathrm{Mj}^{3}\right)$ and four juvenile females $\left(\mathrm{Fj}^{1}, \mathrm{Fj}^{2}, \mathrm{Fj}^{3}, \mathrm{Fj}^{4}\right)$; therefore, data for twelve individuals were entered in to the analysis. Individual identifications were based on the shape of the crest, the eye rings and the white muzzle, as well as the shape of a depigmented skin area on the belly. Since one female gave birth to an infant, at the end of the study the group had thirteen individuals.

Data Collection and Analysis: The group was observed during half- or all-day sessions during the normal zoo exhibit times, from 08:00 hr to 18:00 hr from 01 September through 30 October 2007 (during 30 of the 60 calendar days). The total recording time was $180 \mathrm{hr}$. All the behaviours were assessed via direct observation. Within the group, observation time was identical per individual. Additional behaviours were noted whenever they were observed (ad libitum sampling method). All the feeding, infant-related, agonistic, locomotor, contact, self-directed \& solitary behaviours and vocalization were included this analysis. Observations were categorized into wet and dry periods.

We determined the overall rates of each behavior $(\mathrm{N}$ per individual observation hour). Dominance hierarchies were constructed based on all focal agonistic behaviour and ad libitum sampling.

\section{Results}

Feeding Behaviours: At 10:30 hr and at 14:00 hr, zoo staff feed the animals. Generally, a mixture of fruits (papaw, pineapple, mango, plantains, water melon, lemon, wood apple, apple), sugar cane, sweet potato, cucumber, long beans, gram (a kind of pulses), and cabbage are supplied at the morning meal. In addition, a mixture of rice and bread is supplied for the afternoon meal. Rarely, green leaves and Ipomoea aquatica are supplied. Among these foods their favorites are gram, cabbage, long beans, green leaves and Ipomoea aquatica. There was a massive competition among the group to take above five foods.

Normally, the food tractor comes near to the cage at 10:00 $\mathrm{hr}$ and 13:30 hr. As these times approached, all the animals, especially immatures, were active and the male remained near the gate and checked frequently to see whether the food had been put into the feeding tank (Fig. 1). The other members waited on the hood of the separated room (Fig. 2). When we played a sound of a tractor during non-feeding times, no one reacted to it. When we played it during feeding time, however, all the animals reacted immediately to the sound without any diffidence.

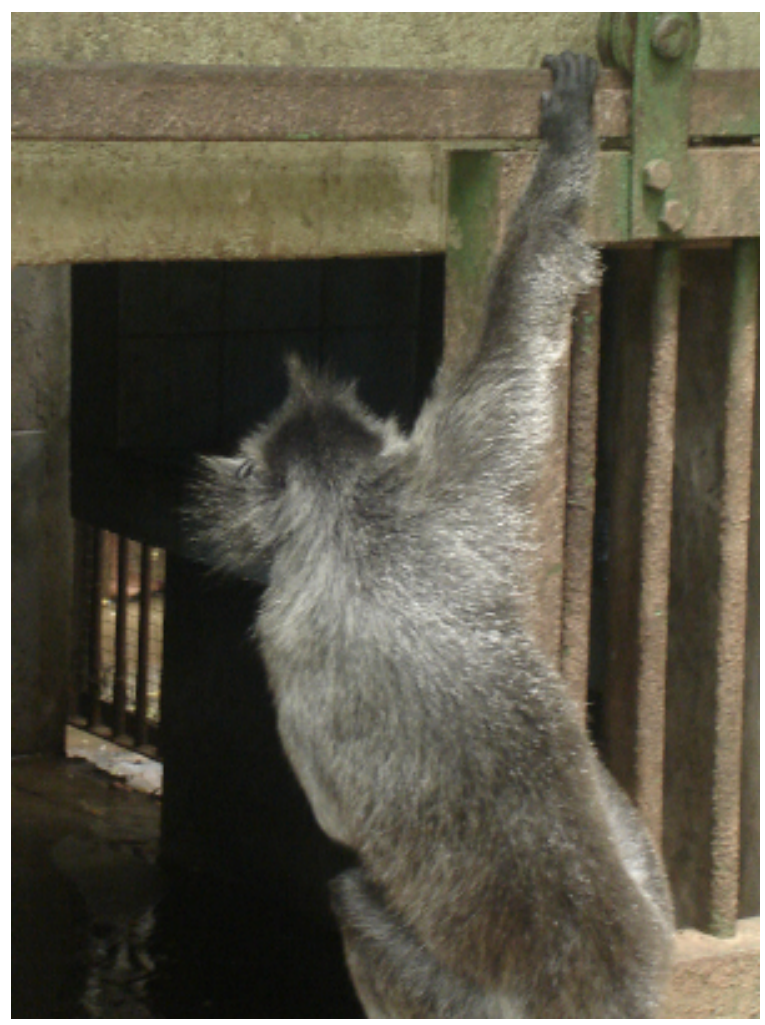

Fig. 01: male checking food 
When the food tractor reached them, most of immatures made a noise that we represent as krēēkk. After the tractor came, these immatures made a sound that we represent as chrēēss. At this time most of individuals were active and were moving around the cage. While feeding, the male took out some foods first and moved aside to eat. Then lactating females approached the tank, selected foods, and ate while sitting there. After that other mature females and older immature males jumped on and strewed all the food around while quarreling. They competed for gram, cabbage and long beans. During this quarreling the immature females took an opportunity to collect food and then went away to eat. In addition, they were gluttonous for green leaves and at that time they frequently took leaves out of the mouth of other members.

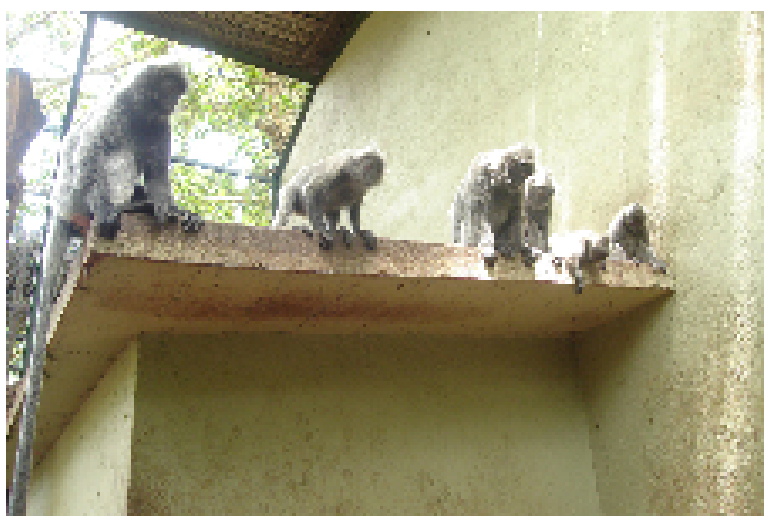

Fig. 02: others waiting for food

The monkeys, and especially the immatures, reacted quickly whenever visitors offered food, a frequent occurrence even though prohibited. Whenever visitors came to near the cage, immatures suddenly raced to the front and begged for food (Fig. 3). Therefore, most of the immatures as well as adults appeared addicted to cooked food.

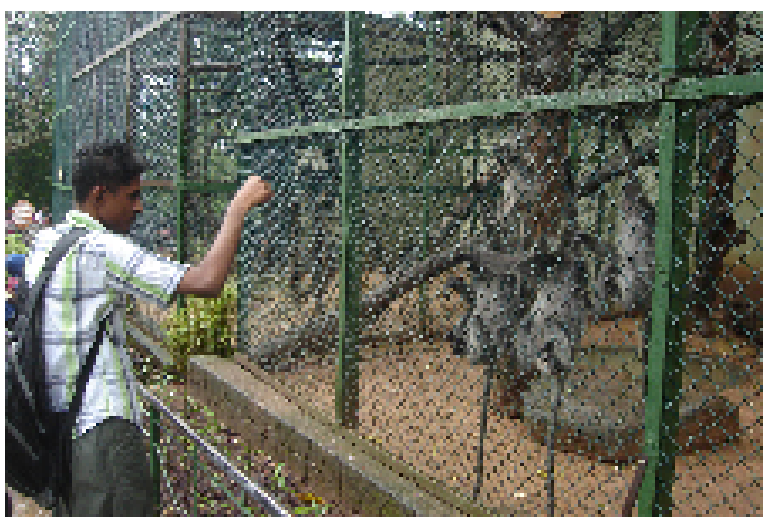

Fig. 03: reaction to the human for food
Agonistic Behaviour \& Dominance Relationships in Adults: During the focal observations, 98 (0.54 interactions per hour) agonistic interactions were observed; we observed displacement on $22(0.12$ interactions per hour) occasions, and individuals taking food from others on 76 (0.42 interactions per hour) occasions. $78 \%$ of these agonistic interactions (displacement and taking food from others) occurred during feeding period. During the observations, Mm* was barking on $6(0.03$ interactions per hour) vocalization interactions.

Based on these relationships (who consistently did what to whom), we constructed a dominance hierarchy among females and immature males. The youngest mature female $\left(\mathrm{Fm}^{*}\right)$ already acquired a medium rank, while the other four of the immature females $\left(\mathrm{Fj}^{1}, \mathrm{Fj}^{2}, \mathrm{Fj}^{3}, \mathrm{Fj}^{4}\right)$, were still at the bottom of the hierarchy. The older immature male $\left(\mathrm{Mj}^{1}\right)$ was above the female dominance hierarchy, but below the adult male (Mm*). The two younger males $\left(\mathrm{Mj}^{2}, \mathrm{Mj}^{3}\right)$ were still low ranking, but above the same-aged immature females. In addition, some agonistic behaviours of the dominant male against visitors were recorded (Fig. 4).

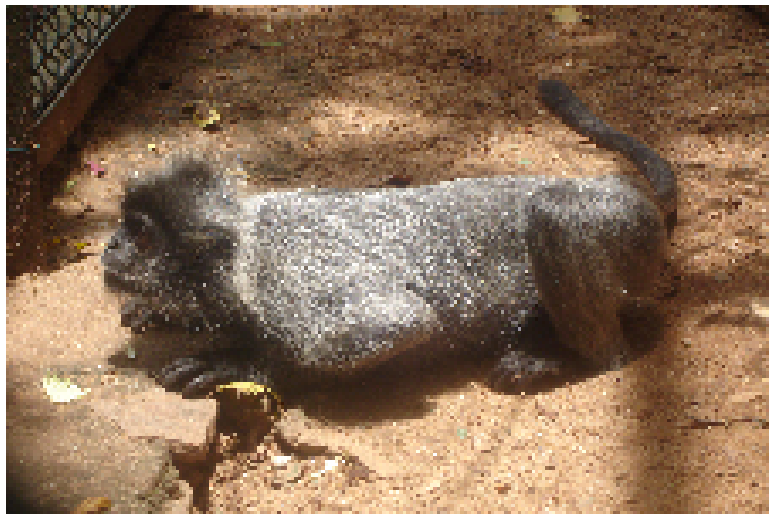

Fig. 04: an agonistic behaviour of the male against visitors

Infant Related Behaviour: During the observations, $\mathrm{Fj}^{4}$ nipple-contacted 154 times (0.85 interactions per hour). $\mathrm{Fm}^{\mathrm{L} 2}$ withdrew nipple contact 32 times $(0.17$ interactions per hour), $\mathrm{Mj}^{3}$ nipple-contacted (Fig. 5) 114 times $(0.63$ interactions per hour $) \& \mathrm{Fm}^{\mathrm{L} 1}$ withdrew nipple contact 40 times $(0.22$ interactions per hour). We observed $\mathrm{Fm}^{\mathrm{L} 2}$ attempt to take her infant $\mathrm{Fj}^{4}$ away from others on 40 (0.22 interactions per hour) occasions; out of these 40 occasions, 12 were rescues. $\mathrm{Fm}^{\mathrm{L} 1}$ attempted to take her infant $\mathrm{Mj}^{3}$ away from others on 16 (0.08 interactions per hour) occasions; out of these 16 occasions, 8 were rescues. 
Most lactating females trended to feed their infants during 08:00 - 09:00 $\mathrm{hr}$ (before the morning feeding time), 11:00 - 12:00hr (after the morning feeding time) and 13:00 - 14:00 $\mathrm{hr}$ (before the afternoon feeding time). In addition, females spent a total of 32 hours ( $18 \%$ of the total observation time) feeding their infants.

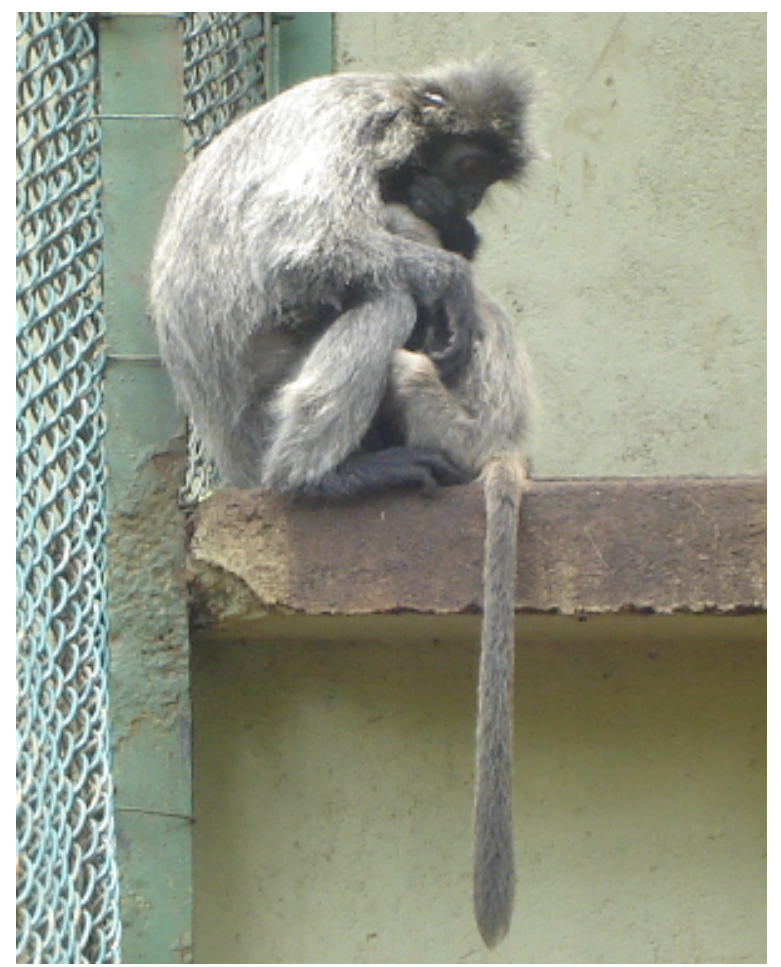

Fig. 05: nipple contact behaviours

The younger immature $\mathrm{Fj}^{4}$ tried to play with other immatures (Fig. 6) and also tried to imitate them. However, most of time the mother $\mathrm{Fm}^{\mathrm{L} 2}$ repressed the infant and took it away. During this time the infant made the chrēesss vocalization. The infant also made this sound while it had been in a dangerous situation. On these occasions, $\mathrm{Fm}^{\mathrm{L} 2}$ reached quickly for the infant and took it away from the danger.

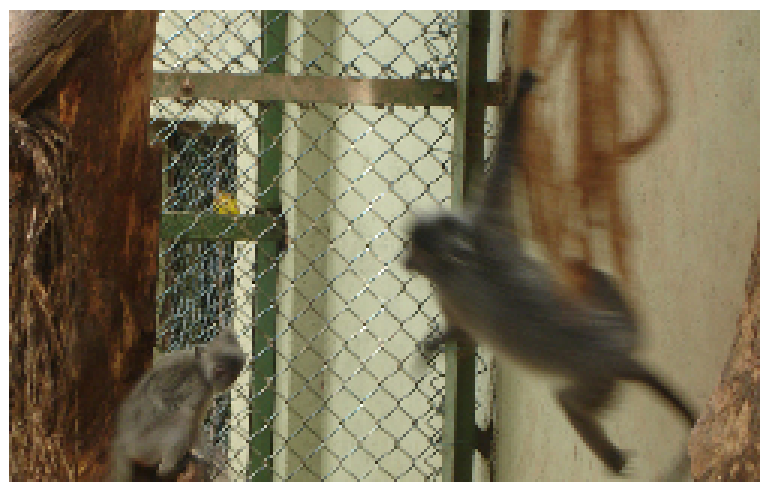

Fig. 06: hanging and climbing behaviours
Locomotor Behaviour: During the focal observations, ( $1 \mathrm{hr}$ for each juvenile) we recorded 1116 locomotory behaviours for 7 individuals (individually $\sim 29$ actions per hour), in wet weather conditions and 3176 for 7 individuals (individually $\sim 82.4$ actions per hour) in dry weather conditions. Here we considered only locomotor behaviours of juveniles for this analysis and omitted all other behaviours (feeding, agonistic, infant-related, contact behaviour, self-directed \& solitary and vocalization).

During both wet and dry days, the group was active from 10:00 hr to $11: 30 \mathrm{hr}$ and 14:00 hr to $15: 00 \mathrm{hr}$. Their feeding time also overlapped at 10:30 hr and 14:30 hr. Before 08:00 hr, between 13:00 - 13:30 hr and after 17:30 $\mathrm{hr}$ the immatures as well as adults were significantly inactive. During the observations, adults never showed suspensory locomotions (i.e., brachiation) or hanging behaviours, while juveniles mostly showed suspensory locomotions.

In addition to the solitary behaviours (Fig. 7), a few grooming behaviours (Fig. 8) and scratching behaviours were recorded. These observations were not entered in to the analysis due to the lack of frequency.

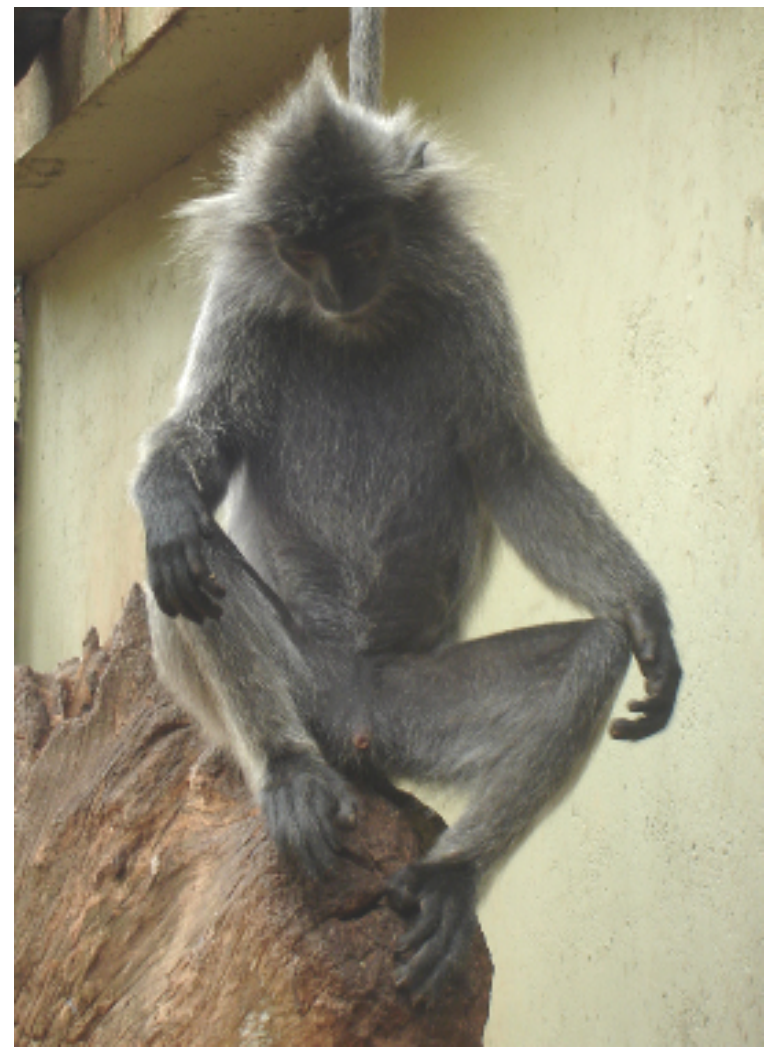

Fig. 07: solitary behaviours 


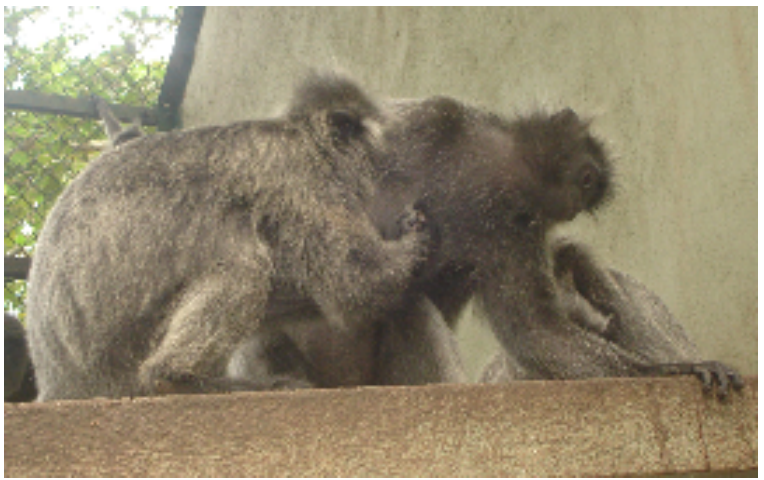

Fig. 08: grooming behaviours

During the observation period, the male and $\mathrm{Fm}^{\mathrm{P}}$ sunbathed for about 10 minutes, evidently to heat their bodies, while clinging to a granite rock (Fig. 9). They rarely showed this behaviour after the afternoon meal.

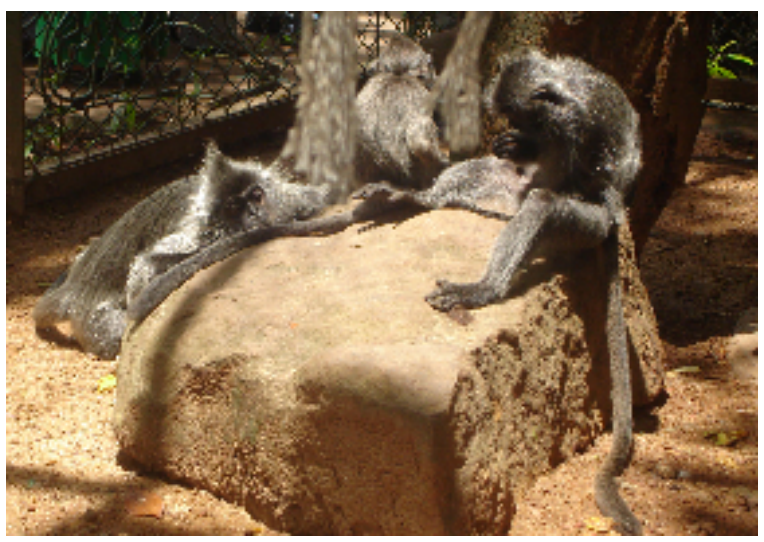

Fig. 09: sun bathing behaviours

\section{Discussion and Recommendations}

The diet of this captive population differed markedly from that of wild populations, in which much higher proportions were leaves, including mature leaves (Roonwal \& Mohnot, 1977; Hock \& Sasekumar, 1979). They spent approximately $20 \%$ of feeding time foraging on Moraceae species. In a field study on the closely related Trachypithecus auratus, teak (Tectona grandis) was the top food species (Kool, 1993), but in our study, the captive leaf monkeys never got $T$. grandis or other native foods. However they liked to eat rarely given green leaves, Ipomoea aquatica, gram, cabbage and long beans. Therefore we assume the taste of given green-leaves; l. aquatica, gram, cabbage and long beans may be similar to those that are eaten in natural habitats. These more natural foods may also be healthier, considering the physiological adaptations of $T$. cristatus to a highly folivorous diet; and there was no obvious evidence of malnutrition or vitamin deficiency. The monkeys' reactions to the tractor sound at feeding times, but not at other times, suggests that this may be a common, learned response in captive populations.

Unlike in wild populations (Bernstein, 1968; Furuya 1961; Medway, 1970; Roonwal \& Mohnot, 1977; Wolf \& Fleagle, 1977), there was a clear dominance hierarchy among the females. The dominance hierarchy of the group, in order from the bottom, was $\mathrm{Fj}^{1}, \mathrm{Fj}^{2}, \mathrm{Fj}^{3}, \mathrm{Fj}^{4}<\mathrm{Mj}^{2}, \mathrm{Mj}^{3}<\mathrm{Fm}^{\mathrm{P}}<\mathrm{Fm}^{\mathrm{L} 1}, \mathrm{Fm}^{\mathrm{L} 2}$ $<\mathrm{Fm}^{*}<\mathrm{Mj}^{1}<\mathrm{Mm}^{*}$. Here the $\mathrm{Fm}^{\mathrm{L} 1}, \mathrm{Fm}^{\mathrm{L} 2}$ was at the medium rank, just below the top male during the feeding time. During feeding times, we could identify the hierarchical order from the bottom; $\mathrm{Fj}^{1}$, $\mathrm{Fj}^{2}, \mathrm{Fj}^{3}, \mathrm{Fj}^{4}<\mathrm{Mj}^{1}, \mathrm{Mj}^{2}, \mathrm{Mj}^{3}<\mathrm{Fm}^{*}, \mathrm{Fm}^{\mathrm{P}}<\mathrm{Fm}^{\mathrm{L}}$, $\mathrm{Fm}^{\mathrm{L} 2}<\mathrm{Mm}^{*}$. Therefore we suppose that the group (especially $\mathrm{Fm}^{*}$ and $\mathrm{Mj}^{1}$ ) allowed $\mathrm{Fm}^{\mathrm{L} 1}, \mathrm{Fm}^{\mathrm{L} 2}$ to acquire foods first because they were feeding infants. The presence of a female hierarchy in this study suggests caution in extrapolating data from captive to wild populations. Alternatively, a female hierarchy might have been overlooked in wild populations and might be detected with more careful observation of marked or otherwise identifiable individuals.

According to agonistic behaviours and dominance relationships, the immature male $\left(\mathrm{Mj}^{1}\right)$ was at the very top of the female dominance hierarchy, but below the adult male [alpha $(\alpha)$ male] $\left(\mathrm{Mm}^{*}\right)$. Therefore we imagine that the immature male $\left(\mathrm{Mj}^{1}\right)$ would become the beta $(\beta)$ male in the near future.

Although males were dominant above same-aged females in this study, it is possible that the dominance was based on size, rather than gender, since $T$. cristatus is moderately sexually dimorphic (c.f. Hemelrijk et al., 2008).

Most lactating females trended to feed their infants during before the morning feeding time, after the morning feeding time and before the afternoon feeding time. Lactating females refrained from feeding their infants before having their own meals. Therefore we believe there is a synchrony between the feeding time and lactating time.

During focal observation of the adult male, we could observe some grooming and unsuccessful copulation behaviours with mature female (Fm*). According to Shelmidine et al. (2007), although genital swellings were most common during the breeding period, there was no strong correlation with oestrus and no particular attraction to the 
males. However, the vulva of Fm* was not swelled in this period, suggesting that she was still not sufficiently mature for a successful copulation.

Finally we would like to recommend giving favorite and more natural foods to this species, not only to minimize refusing \& wasting, but to ensure a healthy diet. In addition, further research should be continued for longer duration with more detail on silvered lutungs. As well, other behavioural studies of animals at the national zoo should be promoted as they may help with ex-situ conservation. Most importantly, visitors should be strictly prohibited from feeding animals and giving non-digestible materials that cause diseases and harm. This restriction should be combined with education to encourage visitors to love animals and observe their behaviours without harm.

\section{Acknowledgements}

The authors wish to thank Professor Colin Groves for reviewing the manuscript and Carola Borries and Mohomed M. Bahir are also acknowledged for providing valuable comments on the earlier draft. We also thank Damith Wijewardena (TNCS), Gayan Wijethunge (TNCS), Dinesh Gabadage (TNCS) and Sanjeewa Lakmal who helped in diverse ways to enrich this work.

\section{Literature Cited}

Bernstein, I. S., 1968. The lutong of Kuala Selangor. Behaviour, 32: 1-16

Borries, C., K. Launhard, C. Epplen, J. T. Epplen and A. P. Winkler, 1999. DNA analyses support the hypothesis that infanticide is adaptive in langur monkeys. Proceedings of the Royal Society of London B, 266: 901-904.

Brotoisworo, E., 1979. The Lutung (Presbytis cristatus) in Pangandaran Nature Reserve: social. adaptation to space. Ph.D. thesis, Kyoto University, Kyoto.

Caton, J. M., 1999. Digestive strategy of the asian colobine genus Trachypithecus. Primates, 40: 311325.

Chivers, D. D., 2001. Functional anatomy of the gastrointestinal tract, 205-249. In: Colobine monkeys: their ecology, behaviour and evolution, Davies, A.G. and J. F. Oates (Eds.). Cambridge University Press: Cambridge.

Curtin, H. C., 1977. Niche separation in sympatric Malaysian leaf-monkeys (Presbytis obscura and
Presbytis melanophos). Yearbook of Physical Anthropology, 1976: 421-439.

Fleagle, J. G., 1977a. Locomotor behaviour and muscular anatomy of sympatric Malaysian leafmonkeys (Presbytis obscura and Presbytis melanophos). American Journal of Physical Anthropology, 46: 297-308.

Fleagle, J. G. 1977b. Locomotor behaviour and skeletal anatomy of sympatric Malaysian leafmonkeys (Presbytis obscura and Presbytis melanophos). Yearbook of Physical Anthropology, 46: 440-453.

Francis, C. M. 2008. A guide to the mammals of southeast Asia. Princeton and Oxford, Princeton University Press.

Furuya, Y. 1961. The social life of silvered leaf monkeys Trachypithecus cristatus. Primates, 3: 41-60.

Geissmann, T., C. P. Groves and C. Roos, 2004. The Tenasserim Lutung, Trachypithecus barbei (Blyth, 1847) (Primates: Cercopithecidae): Description of a live specimen, and a reassessment of phylogenetic affinities, taxonomic history, and distribution. Contributions to Zoology 73.

Glyn, D., 1991. Seed-eating by red leaf monkeys (Presbytis rubicunda) in dipterocarp forest of northern borneo. International Journal of Primatology, 12 (2): 119-144.

Goodman, S. M., 1989. Predation by the grey leaf monkey (Presbytis hosei) on the contents of a Bird's nest at Mt. Kinabalu Park, Sabah. Primates, 30 (1): 127-128.

Hemelrijk, C. K., J. Wantia, and K. Isler. 2008. Female dominance over males in primates: selforganisation and sexual dimorphism. PLoS One 3:e2678. doi:10.1371/journal.pone.0002678.

Hock, L. B. and A. Sasekumar, 1979. A preliminary study on the feeding biology of mangrove forest primates, Kuala Selangor. Malay Nature Journal, 33: 105-112.

Hrdy, S. B., 1974. Male-male competition and infanticide among the langurs (Presbytis entellus) of Abu, Rajasthan. Folia Primatologica, 22: 19-58.

Karunarathna, D. M. S. S., D. A. M. M. Athukorale, W. A. A. D. G. Pradeep, J. K. P. P. D. Jayawardena, K. P. A. Rashintha, W. W. D. H. P. Perera, W. A. D. S. P. Wijesinghe and M. H. S. A. Jayasekara, 2008. 
Some observations on the non-captive faunal diversity in the National Zoological Gardens Dehiwala and its Environs in Sri Lanka. Tigerpaper, 35 (1): 13-21.

Kool, K. M., 1993. The diet and feeding behaviour of the silver leaf monkey (Trachypithecus auratus sondaicus) in Indonesia. International Journal of Primatology, 14 (5): 667-700.

Kunkun, J. G., 1986. Ecology and behaviour of Presbytis thomasi in Northern Sumatra. Primates, 27 (2): 151-172.

Li, Z. Y. and E. M. Rogers, 2004. Social organization of white-headed langurs Trachypithecus leucocephalus in Fusui, China. Folia Primatologica, 75:97-100.

Medway, L., 1970. The monkeys of Sundaland: ecology and systematics of the Cercopithecids of a humid equatorial environment. In: Napier, J. R. and P. H. Napier (Eds.), Old World Monkeys: Evolution, Systematics, and Behavior. London, Academic Press. 513-554.

Newton, P. N. and R. I. M. Dunbar, 2001. Colobine monkey society. In: Groves, C. P. (Ed.) Primate Taxonomy. Washington, D.C., Smithsonian Institution Press. 311-346.

Ostherholz, M., L. Walter and C. Roos, 2008. Phylogenetic position of the langur genera Semnopithecus and Trachypithecus among Asian colobines, and genus affiliations of their species groups. BMC Evolutionary Biology, 8: 58-7.

Phillips, W. W. A., 1980. Manual of Mammals of Sri Lanka, Wildlife and Nature protection Society of Sri Lanka, 389.

Poirier, F. E., 1968. Nilgiri langur (Presbytis johnii) territorial behaviour. Primates. 9 (4): 351-364.

Roonwal, M. and S. M. Mohnot, 1977. Primates of South Asia: ecology, sociobiology and behavior. Cambridge, Massachusets and London, England, Harvard University Press.

Shelmidine, N., C. Borries and A. Koenig, 2007. Genital swellings in Silvered Langurs: What do they Indicate? American Journal of Primatology, 69: 519532.

Somasekaran, T., 1988. The National Atlas of Sri Lanka. Surveys Department Sri Lanka.

Strasser, E. and E. Delson, 1987. Cladistic analysis of cercopithecid relationships. Journal of Human Evoltion, 16: 81-99.
Tague, R. G., 1993. Pubic symphyseal synostosis and sexual dimorphism of the pelvis in Presbytis cristata and Presbytis rubicunda. International Journal of Primatology, 14: 637-654.

Washburn, S. L. 1944. The genera of Malaysian langurs. Journal of Mammalogy, 25: 289-294.

Weinman, A. N., 1957. A zoological guide to the Zoological Gardens of Ceylon. Government press of Ceylon.

Weitzel, V. and C. P. Groves, 1985. The nomenclature and taxonomy of the colobine monkeys of Java. International Journal of Primatology, 6: 399-409.

Wolf, K. E. and J. G. Fleagle, 1977. Adult male replacement in a group of silvered leaf-monkeys (Presbytis cristata) at Kuala Selangor, Malaysia, Primates, 18 (4): 949-955.

Yeager, C. P. and K. Kool, 2000. The behavioral ecology of asian colobines. In: Whitehead P. and C. Jolly (Eds.), Old World Monkeys. New York, N.Y., Cambridge Press, 496-514.

Zhao, Q. and W. Pan, 2006. Male-immature interactions seem to depend on group composition in white-headed langur (Trachypithecus leucocephalus). Acta Ethologica, 9: 91-94. 